\title{
América Latina: el fin de un ciclo (2007-2017)
}

\section{Paula Ruiz*}

\section{Reseña de libro}

Sotillo, J. Á. y Ayllón, B. (coords.). (2017). Las transformaciones de América Latina.

Cambios políticos, socioeconómicos y protagonismo internacional. Madrid: Catarata, Instituto Universitario de Desarrollo y Cooperación

Con el fin de analizar la actualidad política y económica de la región, distintos académicos latinoamericanos y españoles hacen una detallada descripción alrededor de diversos temas, a través de los cuales, llevan al lector a deducir que las principales transformaciones sufridas por la región en los últimos años han sido el producto de los giros políticos ocurridos a lo largo de la última década.

Para su análisis los coordinadores toman como referencia un libro publicado en 2006, por el Instituto Universitario de Desarrollo y Cooperación, editado por Sotillo y Ayllón, titulado América Latina en construcción. Sociedad, politica, economía y relaciones internacionales, en el cual, sus autores dicen que "eran tiempos de cambio, con grandes expectativas para la región tanto en lo económico como en lo político" (p. 10), pero en los que sin duda se reconocían los enormes retos que en materia social seguía enfrentando la región.

Diez años han trascurrido desde aquella publicación hasta la más reciente entrega, coordinada por Ayllón y Sotillo, Las transformaciones de América Latina. Cambios politicos, socioeconómicos y protagonismo internacional (2017), la cual es objeto de la presente reseña. El principal interrogante que plantea este libro es hasta qué punto América Latina se encuentra ante el fin de un ciclo "dorado", marcado desde los primeros años del siglo xxi hasta la crisis financiera de 2008 que se extendió hasta el 2010.

* Doctoranda en estudios políticos. Docente-Investigadora. Facultad de Finanzas, Gobierno y Relaciones Internacionales, Universidad Externado de Colombia, Bogotá (Colombia). [paula.ruiz@uexternado.edu.co].

Para citar esta reseña:

Ruiz, P. (2018). América Latina: el fin de un ciclo (2007-2017) [Reseña: Sotillo, J. Á. y Ayllón, B. (coords.). (2017). Las transformaciones de América Latina. Cambios políticos, socioeconómicos y protagonismo internacional. Madrid: Catarata, Instituto Universitario de Desarrollo y Cooperación]. OASIS, 28, pp. 199-204.

DoI: https://doi.org/10.18601/16577558.n28.12 
Un período en el cual la región se caracterizó por su protagonismo político y económico en el ámbito internacional, así como en su liderazgo en los temas propios al desarrollo.

Dichas transformaciones políticas necesariamente llevan al análisis de otras variables que capítulo tras capítulo reflexionan alrededor de los factores económicos, institucionales, sociales, internacionales e ideológicos que han rodeado los procesos de integración latinoamericanos desde inicios del siglo xxi hasta la actualidad, que llevan a comprender, o al menos a deducir, que en el ámbito internacional los países de la región siguen construyendo su identidad de manera diversa, marcadamente ideológica y confusa, lo cual se evidencia "en la variedad de proyectos y modelos de integración, regionalismo y gobernanza” (BernalMeza, 2017, p. 122) ${ }^{1}$.

Desde diversos puntos de vista, esta publicación analiza el rol que debería ocupar América Latina en el mundo como promotor de políticas de desarrollo y fuente de enormes riquezas, pero en contraste, se evidencia una región con altos índices de desigualdad y pobreza. Según la Cepal (2017), entre el 2002 y el 2008 el número de personas en situación de pobreza pasó de 233 millones a 187 millones, un significativo avance para entonces, sin embargo, de 2008 a 2016 la cifra varió muy poco y a 2016, el número de personas pobres era de 186 millones (p. 88), lo cual refleja el estancamiento en el desarrollo de políticas sociales encaminadas a la reducción de la pobreza.

La América Latina del 2007 vista por el mundo "con grandes expectativas" (Sotillo y Ayllón, 2017, p. 10) en lo económico y en lo político, llega casi fatigada al 2017, enfrentándose a "un contexto de fuertes turbulencias internacionales [que] lleva a describir la situación actual como tiempo de incertidumbres" (p. 10).

\section{LOS CAMBIOS SOCIALES}

En los últimos años, diversos movimientos políticos han venido sacudiendo a la región que entre cambios ideológicos y ajustes económicos sortea la suerte de sus pueblos. Los cambios políticos de inicios del siglo xxI, la mayoría de estos llamados por los autores como la llegada de gobiernos progresistas al poder, aprovecharon una coyuntura económica única ${ }^{2}$ que les permitió alcanzar un mayor protagonismo al interior de sus fronteras gracias, entre otras cosas, a la reivindicación de discursos a favor del individuo. No obstante, tal como lo señalan De Gori, Gómez y Ester (2017), "la fuerza cultural del individuo fue la posibilidad y la debilidad de las propuestas populares progresistas o populistas" (p. 28) ante la incapacidad

1 Bernal - Meza, R. (2017). Las relaciones internacionales de América Latina ante un cambio de época. En Sotillo, J. A. y Ayllón, B. (coords). Las transformaciones de América Latina: cambios politicos, socioeconómicos y protagonismo internacional (pp. 120-148), Madrid: Catarata.

2 Descrita por Bernal-Meza así: "la región se hizo dependiente de las exportaciones de commodities cuyos precios al alza, debidos al crecimiento de la demanda china, generaron un aumento sustancial de las exportaciones y de los ingresos por tal razón, situación que coincidió con el boom de las importaciones chinas de manufacturas, en un período de bonanza que duró hasta la crisis mundial de 2008” (2017, p. 143). 
de sus gobiernos de mantener a largo plazo sus políticas.

Con esta coyuntura, algunos de estos gobiernos lograron financiar grandes proyectos sociales que favorecieron políticas como, por ejemplo, aquellas encaminadas para la disminución de la pobreza. Entre algunos de los casos, se podría mencionar el Programa de Transferencias Condicionadas de Brasil, conocido como el Plan Brasil Sin Miseria, el cual se implementó durante el gobierno de Luiz Inácio Lula Da Silva, un programa que fue incorporado como una política pública del orden nacional que logró "sacar a 28 millones de personas de la pobreza y empujar a otros 36 millones hacia una condición de clase media" (Tassara, Ibarra y Vargas, 2015, p. 31).

Tal como lo señalan de Gori, Gómez y Ester,

Estos gobiernos, si bien surgieron como impugnaciones o respuestas al neoliberalismo, no significaron su accionar político como actores antiglobalización. Por el contrario, aceptaron el beneficio del precio global de los commodities y los recursos naturales, y orientación tanto de la economía como la ampliación del poder estatal, intentando capturar algún beneficio producido por la explotación del petróleo, la minería y los cereales, a través de dinámicas regulatorias (2017, p. 18).
Uno de los análisis adelantados por uno de los investigadores y que permite comprender la dinámica económica de la región, es el del economista Omar de León ${ }^{3}$ quien identifica diversas estrategias de desarrollo implementadas en la región entre 2003-2015, las cuales son el reflejo de los cambios y las dinámicas políticas de la región a lo largo de la última década, clasificando a los países en tres estilos del desarrollo, así:

Un grupo conformado por aquellos países que hoy en día conforman la Alianza del Pacífico, que clasifican como países "que mantuvieron estrategias globales de tipo liberal" ( $\mathrm{p}$. 46), seguidos de "gobiernos de izquierda institucional" que "basan su proceso de desarrollo en la ampliación del mercado interno a partir de medidas de transformación de las estructuras productivas de sus economías" (p. 46) y, por último, gobiernos de izquierda popular, en los cuales se centra principalmente el análisis del libro, con una fuerte presencia estatal "que controla o gestiona los principales productos de exportación que se convierten en la fuente de recursos para lograr las metas del desarrollo social" (p. 47), que responden a un proyecto político de corto y mediano plazo.

En esta última reflexión resulta interesante señalar que los resultados en materia econó-

3 De León, O. (2017). Evolución económica y estrategias de desarrollo en América Latina. En Sotillo, J. A. y Ayllón, B. (Coords.). Las transformaciones de América Latina: cambios politicos, socioeconómicos y protagonismo internacional (pp. 34-68), Madrid: Catarata.

4 Entre los tipos de luchas que lideran los movimientos sociales latinoamericanos, Bringel destaca principalmente: las luchas vinculadas al trabajo, a la transformación de la forma del Estado, luchas vinculadas al territorio y a los recursos naturales, luchas de base territorial vinculadas a conflictos que abarcan ejes como la biodiversidad, la minería, el (neo)extractivismo, el agua o la construcción de infraestructura, luchas vinculadas a la reproducción de la vida, la memoria y la identidad (pp. 114-116). 
mica distan mucho de los resultados en materia social, para Bringel (2017) en América Latina siguen existiendo luchas que se configuran como ejes de conflicto en la región latinoamericana y de las que muy poco se ha hablado desde el punto de vista teórico ${ }^{4}$. Para este autor, los movimientos sociales son una "cartografía de las resistencias y conflictos sociales" (Bringel, 2017, p. 96) por los que atraviesan los países y por lo cual su estatus es el que mejor define la realidad de un país.

Uno de los aspectos más importantes que ha marcado tanto la construcción como la reivindicación de los pueblos en América Latina está alrededor de sus raíces, de su cultura y de su idiosincrasia cuya defensa no ha dejado de ser foco de preocupación ni de discusión por parte de la ciudadanía, pues desde sus raíces más íntimas y humanas, la pobreza continúa paseándose entre poblaciones que viven en la miseria y casi en el olvido de sus gobiernos.

Aunque uno de los aspectos que se señalan a lo largo del libro es el tema de la pobreza, la desigualdad y las necesidades que deben afrontarse para mejorar la calidad de vida de los individuos, el espacio para el análisis de actores no estatales es escaso. Por lo cual, una reflexión ante esto podría ser que a pesar de que en distintos escenarios se reconoce la importancia de los actores no estatales para la construcción de políticas sociales que permitan fortalecer espacios de diálogo y de negociación, lo cierto es que su análisis es limitado, y el intento por evidenciar sus luchas, problemáticas y su rol como constructores de la identidad latinoamericana queda en un segundo plano.

\section{EL FORTALECIMIENTO DE LA COOPERACIÓN SUR-SUR (CSS) LATINOAMERICANA}

Para el período 2014-2017, según la lista de destinatarios de ayuda oficial al desarrollo del Comité de Ayuda al Desarrollo (CAD), 13 de los 22 países de América Latina están en la categoría de países de renta media 5 .

Dos capítulos se centran en analizar las transformaciones sufridas desde América Latina en el plano, tanto político como ideológico alrededor de la cooperación internacional al desarrollo (CID). Tras la búsqueda de una mayor autonomía política, los países de la región fortalecen la cooperación Sur-Sur (css) como herramienta para la consecución de sus intereses en materia de política exterior, al tiempo que definen agendas de desarrollo que respondan a sus intereses, pero también a sus necesidades en materia social.

Javier Surasky ${ }^{6}$ señala que lo que se conoce como la Agenda 2030 o los Objetivos de Desarrollo Sostenible (ODs) son la muestra del

\footnotetext{
5 Los países de renta medida son aquellos que cuentan con un Producto Nacional Bruto per cápita que se encuentra entre los $\$ 4126$ y $\$ 12745$, lo que hace de la región un centro poco atractivo de flujos de cooperación al desarrollo. Para mayor información ver: OECD, (s.f.), DAC List of ODA Recipients. Disponible en línea en http://www.oecd.org/dac/ stats/daclist.htm

6 Desarrolla el capítulo alrededor de un análisis de la aprobación y puesta en marcha de los oDs como una iniciativa latinoamericana. El autor desarrolla el capítulo 3: Cuidado con lo que deseas. América Latina en el umbral de la agenda 2030 (pp. 69- 95).
} 
empeño de los países de la región por ganar un mayor espacio en la toma de decisiones a nivel global en materia de desarrollo y, de esta forma, mejorar su capacidad de negociación, bien sea a través de organismos regionales o en el marco de la Organización de Naciones Unidas.

El proceso surtido por la región latinoamericana para la construcción y aprobación de los oDs -toda una agenda-, que como describe el autor fue pensada desde América Latina con los problemas de la región, cuya importancia radica en la transversalidad de sus objetivos alrededor de tres ejes: económico, social y ambiental, representa hoy en día una importante hoja de ruta que involucra, tanto a países en desarrollo como desarrollados y a diversos actores no estatales.

Esta agenda, que ha sido definida por algunos autores como una agenda global para el desarrollo (Sachs, 2016; Ojeda, 2016; Santander, 2016), incorpora 4 principios que se han alineado a los intereses de los países de la región: el de la universalidad, el de no dejar a nadie atrás, el principio de las responsabilidades compartidas, pero diferenciadas y el principio del trabajo integral.

Si bien América Latina ha sido dinámica frente a la definición de su rol en materia de CID, dos reflexiones quedan en el aire frente a los análisis que abordan, por un lado, Surasky y, por el otro, Ayllón. Por un lado, se cuestiona tanto la eficacia como la capacidad de acción de los gobiernos de la región ante un proceso que exige la incorporación de sistemas de seguimiento continuo, monitoreo alrededor de los 230 indicadores en los que se basan los oDs, e incluso de adaptación en los sistemas nacionales y, por el otro, deja abierto el debate alrededor del tema de la "graduación" de estos para ser beneficiarios de la AOD y la necesidad de continuar fortaleciendo modalidades de cooperación como la Sur-Sur y la triangular ${ }^{7}$.

\section{CONCLUSIÓN}

Una idea general que dejan los autores capítulo tras capítulo es que a pesar de sus avances en materia de integración económica, América Latina sigue siendo presa de los movimientos políticos de sus gobiernos que lo llevan a la deriva. Pasando de la búsqueda de consensos durante la primera década del siglo Xxi, en materia de acuerdos y objetivos comunes en materia de desarrollo, a la mediación sobre las discrepancias alrededor de los problemas internos de los países, tal como ocurre actualmente frente al tema de Venezuela, nación que en materia energética llegó a ser un socio estratégico que determinó la agenda de la región durante el 2006 (Bernal-Meza, 2017), pero que hoy es un problema diplomático para casi todos los países suramericanos.

Si algo evidencian sus autores es que entre el 2007 y el 2017, los países latinoamericanos se movieron entre agendas más liberales y otras más progresistas, pero que en últimas, ambas

En términos generales, la cooperación triangular es una modalidad dentro de la Sur-Sur en la que se involucra un tercer país en desarrollo, o institución internacional que aporta los recursos y que facilita el proceso de transferencia de conocimientos, y de experiencias de un país del sur a otro del mismo nivel de desarrollo. 
buscaban superar sus problemas de pobreza, desigualdad y en la medida de lo posible cumplir con las metas globales para el desarrollo. No obstante, los gobiernos latinoamericanos entraron en una "zona de turbulencias a lo largo de los últimos años" (de Gori, Gómez y Ester, 2017, p. 17), donde sus gobiernos "fueron máquinas de estabilidad política (...) pero también grandes productores de actores y trasformaciones que fueron más allá de su control y conducción” (p. 18).

\section{REFERENCIAS}

Cepal. (2016). Panorama social de América Latina. Santiago de Chile: Naciones Unidas.

Ojeda, T. (2016). Relaciones internacionales y cooperación con enfoque Sur-Sur. Madrid: Catarata.

Sachs, J. (2014). La era del desarrollo sostenible. Bogotá: Planeta.

Santander, G. (2016). Identidades e intereses en la cooperación Sur Sur. Madrid: Catarata.

Sotillo, J. A. \& Ayllón, B. (2017). Las transformaciones de América Latina. Cambios politicos, socioeconómicos y protagonismo internacional. Madrid: Catarata.

Tassara, C.; Ibarra, A. \& Vargas, L. (2015). Protección socialy lucha contra la pobreza en Brasil, Colombia y Chile. ¿Graduarse de los PTC o salir de la pobreza? (C. Tassara, Ed.) Madrid: EUROSociAL. 